\title{
Prognoses after self-harm in youth: exploring the gender factor
}

\author{
Karin Beckman ${ }^{1} \cdot$ Henrik Lysell $^{1} \cdot$ Axel Haglund $^{1,2} \cdot$ Marie Dahlin $^{1}$
}

Received: 1 June 2018 / Accepted: 22 October 2018 / Published online: 7 November 2018

(c) The Author(s) 2018

\begin{abstract}
Purpose Gender differences in youth self-harm are sparsely studied regarding long-term prognoses. We aimed to study the gender differences in effects of adolescent self-harm in early adult life in four domains: 1/family situation, 2/education and employment, 3/mental illness and suicidal behaviour, and 4/suicide and all-cause mortality.

Method A register-based cohort study including all Swedish residents aged 20 during 2001-2005 was performed. Exposure was self-harm at ages 10-20, and outcomes were death and suicide and past-year records of self-harm, marital status/children, education/employment, and mental health at age 30. We used logistic regression for dichotomous outcomes, and Cox regression models for time-dependent outcomes. An interaction term was introduced to detect significant gender effects, in which case we performed stratified analyses.

Results Subjects with self-harm before age 20 had a poorer prognosis for all studied outcomes, and risk estimates were similar for men and women for most outcomes including suicide. Significant interaction terms (ITs) were found, revealing gender differences, for being married $\left(p_{\mathrm{IT}} 0.0003 ; \mathrm{OR}_{\text {men }} 0.6, \mathrm{OR}_{\text {women }} 0.9\right)$, being a parent $\left(p_{\mathrm{IT}}<0.0001 ; \mathrm{OR}_{\text {men }} 0.7, \mathrm{OR}_{\text {women }}\right.$ $1.1)$, receiving unemployment support $\left(p_{\mathrm{IT}}<0.0001 ; \mathrm{OR}_{\mathrm{men}} 2.4, \mathrm{OR}_{\mathrm{women}} 1.8\right)$, and death from any cause $\left(p_{\mathrm{IT}} 0.006 ; \mathrm{OR}_{\text {men }}\right.$ 10.6, $\mathrm{OR}_{\text {women }}$ 7.4).

Conclusions Adolescent self-harm was associated with later life adversities and affected men more than women regarding prognoses for unemployment and certain aspects of the family situation. We found no gender difference for the effect of self-harm on the risk of suicide. Future suicide risk should not be underestimated in young self-harming women.
\end{abstract}

Keywords Self-harm $\cdot$ Suicide $\cdot$ Mental illness $\cdot$ Youth $\cdot$ Prognosis

\section{Introduction}

Self-harm and suicidal behaviour are common among young people. In other studies of self-harm, various terms are used. In this article the term "self-harm" is used, defined as direct self-injurious behaviour regardless of the degree of suicidal intent. If the referred studies use other definitions, this is stated in the text. In population-based studies, around 10\% of youth report a history of self-harm [1, 2]; in a European multi-centre study of self-harm, $13.4 \%$ of female adolescents

Karin Beckman

karin.beckman@ki.se

1 Department of Clinical Neuroscience, Centre for Psychiatry Research, Karolinska Institutet and Stockholm Health Care Services, Stockholm County Council, St. Goran, 11281 Stockholm, Sweden

2 National Board of Forensic Medicine, Alfred Nobels Allé 41, 14152 Huddinge, Sweden and $4.3 \%$ of young men had a lifetime history of self-harm [3]. Onset of suicidal behaviour is most often in late adolescence or the early twenties [4]. Self-harm and suicidal behaviour in the identity-forming period of adolescence are likely to affect a person's adult life in several respects, such as life expectancy, the establishment of a family, the pursuit of a career, and mental health status. Previous studies have reported increased risks of violence/criminal behaviour, mental and physical health problems, and need for social support and welfare benefits [5-10].

There are considerable gender differences in suicidal behaviour during youth and young adulthood, with suicidal ideation and suicide attempts being more common in young women [11]. The same is true for non-suicidal self-injury (NSSI), for which there is a larger gender difference in clinical than in community samples [12]. For medically severe suicide attempts, the gender difference is less pronounced [11]. The "suicidal gender paradox" points to the fact that, despite the higher prevalence of self-harm among women 
compared to men, men more often die from suicide than do women [11-14]. Women have higher rates of internalising disorders, e.g. depression and anxiety, which are associated with suicidal ideation and suicide attempts. Externalising disorders linked to more aggressive and impulsive behaviour are more pronounced among suicidal men, and may partly explain the more lethal outcomes of their suicidal behaviour [14].

Since it has been suggested that both NSSI [12] and suicidal behaviour $[11,14]$ varies between men and women with regard to its functions, prevalence, and associated variables, long-term effects may also differ between the genders. The effects of adolescent self-harm on various important measures of quality of life in adulthood have not been extensively explored with regard to gender. In a follow-up study in New Zealand of individuals who had made a suicide attempt before the age of 24, a large variety of psychiatric, physical and social factors were assessed at age 38 . Gender differences were found only for physical functioning and metabolic syndrome. The effects of suicide attempt were otherwise the same in both sexes [7]. As in other studies, the number of suicide attempters was limited; thus, studies of larger samples would be valuable.

The probability of setting up stable relationships as well as becoming a parent might be affected among those who self-harm. A previous study explored future family situation, among other outcomes, after adolescent suicide attempts, and found no significant associations with marital status or parenthood in adulthood between suicide attempters and non-attempters of both genders [9]. However, there is evidence among young male suicide attempters of associations with later instability of intimate relationships, and with violent behaviours towards partners [6]. An increased risk of being victimised by romantic partners is also reported for young suicide attempters, without a gender difference [7].

Suicidal behaviour and self-harm, and also mental distress as such, may have negative effects on academic performance, and affect future prospects of engaging in higher education $[9,15]$. We have found no evidence that such effects differ between men and women who had attempted suicide at a young age [9]. Young suicide attempters face difficulties in labour market integration [7, 8]. In a Swedish national cohort there were significant interactions between gender and suicide attempts for young people on longterm sick leave or disability pension and unemployment, but with only marginally different risk estimates [8].Longterm mental health problems, such as depression, substance dependence, and use of mental health care and prescribed psychotropic drugs, has been reported after suicide attempts and self-harm at an early age $[5,7,10,16]$. Substance use is associated with a history of suicide attempts in young women but not in men [5]. To our knowledge, in-depth analyses of gender differences in future mental illness after self-harm during youth have not been performed.

Self-harm is an important risk factor for suicide [2]. Men die from suicide more often than women, and women selfharm more often than men, but whether the risk-increasing effect of self-harm, or its signal value, differ between men and women is not clear. Since self-harm is less common among young men, it is possible that self-harm in young men is a more severe indicator of later adverse outcomes, such as suicide. The risk of further suicidal behaviour in early adulthood is increased by adolescent self-harm, but gender differences have either not been detected or have pointed in different directions $[5,7,17]$.

The aim of the present study was to use national registers to investigate gender differences in long-term prognoses after self-harm leading to hospitalisation in youth across four domains: 1/family situation, 2/education and employment, 3/mental illness and suicidal behaviour, and 4/ suicide and all-cause mortality.

\section{Methods}

We conducted a cohort study based on linked Swedish population registers. We included all individuals who were registered as residents in Sweden between 2001 and 2005 and aged 20 years at the time of inclusion. Data on registered residents were taken from The Longitudinal Integration Database on Social Insurance and Labour Market Studies (LISA). This register, which contains sociodemographic data on all Swedish residents above the age of 16 since 1990, is held by Statistics Sweden. We excluded individuals who had immigrated or emigrated between 10 and 20 years of age since possible exposures during that time would have been undetected.

\section{Exposures}

All events of self-harm leading to hospitalisation, International Classification of Diseases (ICD-10) codes X 60-84 and Y 10-34, as registered in the National Patient Register (NPR), were included if they occurred between ages 10 and 20. The register is held by the National Board of Health and Welfare and contains data on diagnosis upon discharge from inpatient care since 1987 and outpatient care since 2001. No information on suicidal intent at the self-harm event is available from registers.

Data on the sex of the individuals were gathered from LISA (male/female). Information on country of birth derives from the Total Population Register (TPR), and was dichotomised as birth outside Sweden or the other Nordic countries (e.g. Finland, Norway, Denmark and Island) y/n. The TPR 
was established in 1968 and contains data on, e.g. country of birth, age and sex, and is held by Statistics Sweden.

\section{Outcomes}

We collected data on social and health status during the calendar year when the individuals were 30 years of age. We organised the included outcomes into 4 domains:

\section{Domain 1}

Family situation, where information on civil status during the age-30 calendar year was collected from LISA. The variables were operationalised as married yes/no (y/n), divorced/ widowed $y / n$ and unmarried $y / n$, and also parental status (as having children $\mathrm{y} / \mathrm{n}$ ).

\section{Domain 2}

Educational and employment status, where data on achieved level of education were collected from Sweden's Educational Register. The register contains data on the highest level of education of all Swedish citizens since 1985. The highest level of education is operationalised as low ( $\leq 9$ years), medium (9-12 years), and high ( $\geq 12$ years, higher education). Data on employment status were taken from LISA. The variable unemployment $(\mathrm{y} / \mathrm{n})$ was defined as having received unemployment benefits at some point during the age-30 calendar year. We defined sick leave $(\mathrm{y} / \mathrm{n})$; as having received sick-leave benefits during the calendar year, which requires at least one period of sick leave exceeding 14 days.

\section{Domain 3}

Mental illness and self-harm Psychiatric care during past year was defined as having made any visit to a specialised psychiatric care unit $y / n$, inpatient or outpatient, during the age-30 calendar year, as recorded in the NPR. We also used any record in the NPR of a diagnosis of substance use disorder (F 10-19, thus including alcohol, as well as legal or illegal drugs) and of self-harm (X60-84 or Y10-34) during the past calendar year at the age of 30 .

\section{Domain 4}

Suicide during follow-up defined as death by suicide (X6084) or with underdetermined intent (Y10-34). The information was taken from the Cause of Death Register (CDR), which includes all deaths since 1952 of individuals, registered in Sweden at time of death, which is held by the National Board of Health and Welfare. Information on death from any cause during follow-up was gathered from the CDR and is included in all cases of death.

\section{Statistical analyses}

We performed Chi-squared tests to assess differences between the included variables among women and men. To analyse the probability of the outcomes appearing after selfharm, we used logistic regression models, with individuals not exposed to self-harm before age 20 as the reference category. In all the analyses, we included an interaction term for the variable in question and for sex. If the interaction term was statistically significant, we present separate analyses for women and men. The analyses were adjusted for country of birth. In the analyses of death from any cause and suicide before age 30, Cox proportional hazard models were performed, and hazard ratios (HR) were calculated. Time at risk was considered as the time from the 1st of January of the year when the individual turned 20 up to time of death, or time of emigration, or end of follow-up (end of the year when the individual turned 30).

\section{Ethical statement}

Ethical approval was obtained from the Stockholm Regional Ethics Review Board (2012/1669-31/5 and 2016/2021-32).

\section{Results}

There were 496,152 individuals in the cohort, and 241,597 (48.7\%) were women. Before the age of 20, 5857 (1.2\%) individuals had a record of self-harm in inpatient care; 4237 women $(1.8 \%)$ and 1620 men $(0.6 \%)$. At age $30,23,450$ (4.7\%) were lost to follow-up, due to death or emigration; for men, loss to follow-up was higher among those with early self-harm (Table 1). Mean age at the first self-harm event was $16.8(\mathrm{SD} \pm 2.2)$ years among women and $17.2(\mathrm{SD} \pm 2.4)$ years among men. Descriptive data are presented in Table 1, and the models displaying significant interaction terms and requiring stratified analyses are shown in Table 2.

Self-harm in adolescence implied higher odds of being divorced/widowed (adjusted odds ratio (AOR) 2.6; 95\% CI 2.3-2.9) for both genders. There was a significant interaction between gender and being married; self-harm affected the odds more for men (AOR 0.6; 0.5-0.7) than for women (AOR 0.9; 0.8-0.9). Among men, the odds for being a parent at age 30 was lower for those with self-harm compared to those without (AOR 0.7; 0.6-0.8), but self-harm did not affect the odds of being a parent among women.

Self-harm before age 20 affected the probability of achieving a high education at age 30, similarly among women and men, with adjusted ORs of $0.4 ; 0.3-0.4$, 
Table 1 Descriptive data on the cohort of all individuals living in Sweden at age 20 between 2001 and $2005(n=496,152)$

\begin{tabular}{|c|c|c|c|c|c|c|}
\hline & \multicolumn{3}{|l|}{ Female } & \multicolumn{3}{|l|}{ Male } \\
\hline & $\begin{array}{l}\text { Self-harm } \\
\text { before age } 20 \\
\%(n)\end{array}$ & $\begin{array}{l}\text { No self-harm } \\
\text { before age } 20 \\
\%(n)\end{array}$ & $p$ value & $\begin{array}{l}\text { Self-harm } \\
\text { before age } 20 \\
\%(n)\end{array}$ & $\begin{array}{l}\text { No self-harm } \\
\text { before age } 20 \\
\%(n)\end{array}$ & $p$ value \\
\hline Total & $1.8(4237)$ & $98.2(237,360)$ & & $0.6(1620)$ & $99.4(252,935)$ & \\
\hline Loss to follow-up due to death or migration & $5.0(212)$ & $4.8(11,452)$ & 0.59 & $10.6(171)$ & $4.6(11,615)$ & $<0.0001$ \\
\hline Suicide between age $20-30$ years & $1.8(76)$ & $0.1(249)$ & $<0.0001$ & $4.5(73)$ & $0.3(793)$ & $<0.0001$ \\
\hline All-cause death between 20 and 30 & $2.6(112)$ & $0.4(849)$ & $<0.0001$ & $9.4(152)$ & $0.9(2336)$ & $<0.0001$ \\
\hline Follow-up at age 30 & $N=4025$ & $N=225908$ & & $N=1449$ & $N=241,320$ & \\
\hline Married status & $25.8(1038)$ & $28.3(63,829)$ & 0.0007 & $12.6(182)$ & $18.2(43,808)$ & $<0.0001$ \\
\hline Divorced/widowed status & $8.5(342)$ & $3.3(7404)$ & $<0.0001$ & $3.3(48)$ & $1.6(3838)$ & $<0.0001$ \\
\hline Parental status & $52.9(2129)$ & $51.6(116,480)$ & 0.093 & $24.7(358)$ & $31.2(75,310)$ & $<0.0001$ \\
\hline Educational level low ( $\leq 9$ years) & $22.3(897)$ & $6.5(14,597)$ & $<0.0001$ & $32.6(472)$ & $10.4(25,004)$ & $<0.0001$ \\
\hline Educational level medium (9-12 years) & $49.9(2007)$ & $42.9(96,915)$ & $<0.0001$ & $51.4(744)$ & $54.4(131,261)$ & $<0.020$ \\
\hline Educational level high (higher education) & $27.5(1101)$ & $50.3(112,712)$ & $<0.0001$ & $15.0(215)$ & $34.6(82,700)$ & $<0.0001$ \\
\hline Unemployment during past year & $20.9(840)$ & $12.8(28,907)$ & $<0.0001$ & $25.3(366)$ & $12.0(28,867)$ & $<0.0001$ \\
\hline Sick-leave during past year & $12.4(501)$ & $2.5(5622)$ & $<0.0001$ & $11.6(168)$ & $2.5(6034)$ & $<0.0001$ \\
\hline Psychiatric care during past year & $25.1(1012)$ & $4.9(11,139)$ & $<0.0001$ & $23.9(346)$ & $4.3(10,353)$ & $<0.0001$ \\
\hline Diagnosis of substance use during past year & $2.0(81)$ & $0.2(514)$ & $<0.0001$ & $3.9(56)$ & $0.5(1127)$ & $<0.0001$ \\
\hline Self-harm during past year & $2.6(106)$ & $0.2(343)$ & $<0.0001$ & $2.4(34)$ & $0.1(338)$ & $<0.0001$ \\
\hline
\end{tabular}

Table 2 Prognoses after adolescent self-harm for the cohort of all individuals living in Sweden aged 20 between 2001 and 2005 ( $n=496,152)$ by use of logistic regression models and Cox regression models

\begin{tabular}{|c|c|c|c|c|c|}
\hline & $\begin{array}{l}\text { Self-harm crude } \\
\text { OR }(95 \% \mathrm{CI})\end{array}$ & Self-harm Adj ${ }^{\mathrm{a}}$ OR (95\% CI) & $p$ interaction term & $\begin{array}{l}\text { Female self-harm } \\
\text { before age } 20 \mathrm{Adj}^{\mathrm{a}} \\
\text { OR }\end{array}$ & $\begin{array}{l}\text { Male self-harm } \\
\text { before age } 20 \mathrm{Adj}^{\mathrm{a}} \\
\text { OR }\end{array}$ \\
\hline \multicolumn{6}{|l|}{ Follow-up at age 30} \\
\hline $\begin{array}{l}\text { Suicide between } 20 \text { and } \\
30 \text { years }\end{array}$ & $12.1(10.2-14.4)^{\mathrm{b}}$ & $15.9(13.4-19.0)^{\mathrm{b}}$ & 0.462 & & \\
\hline $\begin{array}{l}\text { All-cause death between } 20 \\
\text { and } 30 \text { years }\end{array}$ & $7.0(6.2-8.0)^{\mathrm{b}}$ & $9.0(7.9-10.2)^{\mathrm{b}}$ & $0.006^{*}$ & $7.4(6.1-9.0)^{* b}$ & $10.6(9.0-12.4)^{* \mathrm{~b}}$ \\
\hline Married status & $0.96(0.9-1.0)$ & $0.8(0.8-0.9)$ & $0.0003 *$ & $0.9(0.8-0.9)^{*}$ & $0.6(0.5-0.7)^{*}$ \\
\hline Divorced/widowed status & $3.1(2.8-3.4)$ & $2.6(2.3-2.9)$ & 0.06 & & \\
\hline Parental status & $1.2(1.1-1.3)$ & $0.97(0.9-1.0)$ & $<0.0001 *$ & $1.1(0.99-1.1)$ & $0.7(0.6-0.8)^{*}$ \\
\hline $\begin{array}{l}\text { Low education level } \\
\text { ( } \leq 9 \text { years })\end{array}$ & $3.6(3.4-3.8)$ & $4.1(3.9-4.4)$ & 0.987 & & \\
\hline $\begin{array}{l}\text { High education level (uni- } \\
\text { versity) }\end{array}$ & $0.4(0.4-0.5)$ & $0.4(0.3-0.4)$ & 0.171 & & \\
\hline $\begin{array}{l}\text { Unemployment benefits dur- } \\
\text { ing past year }\end{array}$ & $2.0(1.9-2.1)$ & $1.9(1.8-2.1)$ & $<0.0001^{*}$ & $1.8(1.6-1.9)^{*}$ & $2.4(2.2-2.8)^{*}$ \\
\hline Sick-leave during past year & $5.4(5.0-5.9)$ & $5.4(5.0-5.9)$ & 0.372 & & \\
\hline $\begin{array}{l}\text { Psychiatric care during past } \\
\text { year }\end{array}$ & $6.8(6.4-7.3)$ & $6.6(6.2-7.0)$ & 0.293 & & \\
\hline $\begin{array}{l}\text { Diagnosis of substance use } \\
\text { during past year }\end{array}$ & $7.3(6.1-8.7)$ & $8.8(7.4-10.5)$ & 0.783 & & \\
\hline Self-harm during past year & $18.0(15.0-21.6)$ & $17.6(14.6-21.2)$ & 0.861 & & \\
\hline
\end{tabular}

*Significant at $5 \%$ level

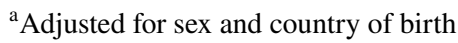

${ }^{\mathrm{b}}$ Hazard ratio HR (95\% CI) 
respectively. Receiving unemployment benefits was prevalent after self-harm: with adjusted OR of 1.9; 1.8-2.1. The interaction effect with gender was significant, with a higher OR for men $(2.4 ; 2.2-2.8)$ than for women $(1.8 ; 1.6-1.9)$.

Among those with self-harm, the probability to have a past-year history of psychiatric care at age 30 was higher with AOR of 6.6 (6.2-7.0). The odds ratio among those with self-harm before age 20 for having a diagnosis of a substance use disorder during the past year at age 30 was 8.8 (7.4-10.5). There were similar effects of early self-harm on both outcomes for women and men. The odds ratio of having at least one event of self-harm during the past year was elevated for those with an early history of self-harm (AOR 17.6 (14.6-21.2)), with a similar effect on women and men.

The total number of suicides in the cohort, recorded at follow-up between age 20 and age 30, was 1191. Among the women who had self-harmed, $76(1.8 \%)$ individuals had died from suicide, and among the men 73 (4.5\%) (Table 1). The hazard ratio (HR) for death from suicide before age 30 was 12.1 , with a $95 \%$ confidence interval of 10.2-14.4, after self-harm, and was higher after adjustment for sex and country of birth (HR 15.9; 13.4-19.0). There was no significant interaction between self-harm and gender regarding the risk of suicide. But there was a significant interaction between gender and self-harm regarding the risk of death from any cause; self-harm implied a slightly higher elevation of risk of death among men (adjusted HR 10.6; 9.0-12.4).

\section{Discussion}

In this national cohort, we were able to investigate whether the long-term effects of adolescent self-harm (before age 20) on adult life differed between men and women in four domains: marital status and children, education and employment, mental illness and self-harm, as well as death. We found overall associations between adolescent self-harm and the outcomes in all domains, but gender differences in only two; the probability was lower among men to be married and to be a parent, and higher to receive unemployment benefits. The risk of all-cause mortality between ages 20 and 30 was more affected by previous self-harm in men, but the effect on suicide risk did not differ according to gender. The results suggest that self-harm has a similar significance as a warning signal for the risk of suicide and long-term mental illness in men and women.

\section{Gender differences in self-harm}

In the present cohort, the proportion of young women who had self-harmed as adolescents was considerably higher than that of men. As our cohort was based on self-harm events that had led to hospitalisation, it is possible that the self-harm acts included were medically severe. It has been suggested that, among more medically serious cases of suicide attempts, the gender difference is smaller [11]. In a meta-analysis of gender differences in non-suicidal selfinjury, an elevated prevalence of self-harm among women compared to men was detected, but with a smaller effect size than expected [12]. The gender difference was more pronounced in clinical samples, and the authors discuss the possibility that women are more inclined to seek medical care in cases of self-harm.

It is possible that gender differences can partly be explained by differences in help-seeking behaviour, perhaps explained by the perception of self-harm as a stigma by men $[18,19]$. Other reasons for a higher prevalence of self-harm among young women than men could be the higher incidence of mental disorders, such as depression and anxiety among adolescent women. In a Swedish survey from the 1990s the incidence of depression in school girls 16-17 years was four times that of the boys [20]. In a more recent American national survey, the incidence of depression among women aged 12-17 was around three times that of men [21]. In the latter study around $15 \%$ reported a suicide attempt in their first episode of depression, confirming previous findings regarding the close associations of mental disorders with self-harm and suicidal behaviour [22]. A model for better understanding of the high prevalence of depression in young women has been proposed, where a vulnerability-stress hypothesis has been presented [23]. A combination of genetic, affective and cognitive vulnerability can result in depression, together with stressful life events, which are more frequently reported by adolescent women. It has been suggested that described cognitive vulnerability, e.g. rumination or negative beliefs about one's own worth, competence or body, contribute to higher levels of depression in young women.

\section{Family situation}

Adolescent self-harm was found to be negatively associated with the probability of developing a stable family situation, with higher rates of divorce and lower rates of being married at age 30 for both genders. For men who had self-harmed, there was a lower likelihood of marriage or for being a parent than for women. A suicide attempt before age 18 has previously been found to be related to later relationship instability and also to aggressiveness towards romantic partner among men [6]. The authors discuss the role of impulsive aggression, which might play a larger role in male self-harm or suicidal behaviour. It is possible that gender differences in factors associated with youth suicidal behaviour, e.g. impulsiveness and aggression for men and depression and anxiety for women [14], have an impact on differences in the prevalence of static family situations in later life. The role of 
aggression in self-harm behaviour may however need more analysis, it is possible that aggression is expressed differently among women, and that aggression may not have been acknowledged or studied among women.

\section{Educational and employment status}

Men with self-harm in youth were significantly more likely to receive unemployment benefits than their women counterparts; odds ratios for men were 3.7 and for women 2.7, with non-overlapping confidence intervals. A previous study describes negative effects on later occupational and educational markers for both genders from self-harm [24]. Further, an earlier study concluded that gender did not affect the elevated prevalence of adult unemployment after youth suicide attempts [7]. However, in a Swedish long-term followup after suicide attempt at a young age, women were more likely than men to have taken sickness absence or disability pension, and men were more likely to be unemployed [25]. It is possible that young women present with more mental health problems and are hence introduced to the sick-leave benefit system to a greater extent than men are. There is also a possibility that this finding reflects a Swedish phenomenon, possibly an effect of aspects of the social welfare system, which we have no means to further discern. We found no gender effect on the risk of having received sick-leave benefits during the past year at age 30 , which is in line with our findings on mental health outcomes.

\section{Mental illness and self-harm}

In the mental illness and self-harm domain, there was a clear effect of adolescent self-harm, which was similar for men and women, for past-year history of psychiatric care, and also for being diagnosed with substance abuse. Substance use in adulthood after self-harm in adolescence has previously been reported [26], but we could not replicate previous findings from a study of a New Zealand cohort, which reported an increased risk of substance use only among female adolescents with suicidal behaviour [5]. Among military recruits in Israel, the prognosis for those who had been treated after a suicide attempt in adolescence was worse among men than women, especially with respect to mental illness [27]. The risk of adult non-lethal self-harm did not differ between men and women. Contradictory evidence of the effect of gender on repetition of self-harm has previously been presented, but the different gender effects have in general had small effect sizes [17]. In this large-sized cohort with national coverage, where the estimates and confidence intervals suggest rather robust findings, the similarity in the effect of self-harm on women and men should be of help for future research.

\section{Suicide}

Self-harm during adolescence was found to be associated with a high rate of suicide in young adulthood, as expected. This association was roughly the same for both genders. Death by suicide occurred more often among men than women; however, our results indicate that self-harm that requires hospitalisation is an equally strong warning sign for young women and young men concerning the long-term risk of death by suicide. Gender differences have previously been reported; in a large follow-up of self-harm attendees of all ages in emergency departments, the standardised mortality rates (SMRs) for women were almost twice as large as for men, even though suicide after self-harm was more common among men [28]. Men and women have also been studied separately in order to address differences regarding the factors predictive of suicide after a suicide attempt, suggesting that advancing age, high suicidal intent, and previous or current psychiatric contact were risk factors for women only, and having repeated self-harm and making a violent index attempt were particular male risk factors [29]. Excess deaths from any cause have been shown to be higher among men than women [30], which was also noted in the present study.

In summary, in long-term follow-up after adolescent selfharm, effects compared to non-self-harm were obvious in all four domains: 1 /family situation, $2 /$ education and employment, 3/mental illness and self-harm, and 4/suicide and allcause mortality. The effect of gender, however, was evident regarding the adult family situation and unemployment, but the effects on psychiatric morbidity and suicide were similar among men and women. Self-harm may be associated with mental illness in similar ways in both men and women, and thus provide an equally strong warning sign of later mental illness and suicide for both genders. However, self-harm could have different associations for young men and women in terms of social disadvantages or personality features, which may be manifested in differing long-term effects in the social/occupational domains.

\section{Strengths and limitations}

A major strength of the present study is its use of national registers, which provide non-biased data with regard to region and data collection, and further give strong enough statistical power to allow for analyses of a wide range of outcomes.

Some limitations should be noted. The patient register contains data on ICD-codes for self-inflicted harm, but we have no information on suicidal intent. Thus, we have chosen to use a concept of self-harm that includes events with and without suicidal intent. We also included events involving uncertain intent. Likewise, our suicide outcome measure included uncertain verdicts on intent. There is a possibility 
that this might overestimate the prevalence of suicide, which we decided was preferable to an underestimation [31]. Further, when estimating outcomes at age 30 , only subjects still alive were included in the analysis. Since more males then females with self-harm, notable due to suicide, were lost to follow-up, a selection bias may have been introduced. The outcomes at 30 would probably have been more severe if these males had remained in the study.

Only self-harm events that had led to hospitalisation were included, so our results are not valid for the major part of self-harm events that are never presented at health care or do not give rise to inpatient care [3]. One can assume that our sample of young adults with experience of inpatient care after self-harm would differ from a community sample of self-harmers in several aspects. A more severe injury and a pronounced suicidal intention probably enhance the possibility of admission to hospital after self-harm, but other factors may also contribute, e.g. co-morbidity with severe mental disorders, level of concern surrounding the adolescent, and the possibility to hide the self-harm from others, or in other ways avoid contact with hospitals. Unfortunately, to speculate on the effect of these factors is beyond the scope of this register-based study.

In transgender and gender dysphoric youth, non-suicidal self-harm and suicidality rates are elevated [32, 33]. These individuals may have been misclassified in the present study; we had no data on transgender or non-binary gender identity in the registers used. Prevalence numbers are low [34]; hence, results for non-transgender subjects are unlikely to be affected. Importantly, however, conclusions cannot be drawn for transgender and non-binary people, and, since prevalence numbers for this group are rising [34], future research may be needed for them to be considered.

\section{Conclusions}

The effect of self-harm in adolescence on young adult life is large in several domains. Our findings suggest that schools, caregivers and social services should pay attention to the psychiatric, social and academic needs of adolescents who self-harm, in order to support their transition into adulthood. The elevated prevalence of self-harm in female adolescents compared to male was confirmed, and further studies are needed to explain the gender difference. To self-harm before age 20 implies a higher risk increase for men than for women in certain family and occupational aspects during adulthood, and further research is needed to confirm results and to investigate possible mechanisms. Overall, prognoses in the four domains were similar in men and women, which indicate that future studies on the prognosis of self-harm might explore both genders together. Importantly, although men are at higher risk of suicide death overall, the signal value of self-harm on suicide risk is just as important among women.

Author contributions MD initiated the study and provided funding. $\mathrm{HL}$ managed the dataset, and $\mathrm{KB}, \mathrm{HL}$ and $\mathrm{AH}$ performed the statistical analyses. KB and MD drafted the manuscript. All authors took part in interpretation of the data and co-wrote the manuscript.

Funding The study was supported by grants provided by Stockholm County Council (PPG), and the Bror Gadelius Foundation.

\section{Compliance with ethical standards}

Conflict of interest The authors declare that they have no conflict of interest.

Open Access This article is distributed under the terms of the Creative Commons Attribution 4.0 International License (http://creativeco mmons.org/licenses/by/4.0/), which permits unrestricted use, distribution, and reproduction in any medium, provided you give appropriate credit to the original author(s) and the source, provide a link to the Creative Commons license, and indicate if changes were made.

\section{References}

1. Hawton K, Rodham K, Evans E, Weatherall R (2002) Deliberate self harm in adolescents: self report survey in schools in England. BMJ 325(7374):1207-1211

2. Hawton K, Saunders KE, O'Connor RC (2012) Self-harm and suicide in adolescents. Lancet 379 (9834):2373-2382. doi:https ://doi.org/10.1016/S0140-6736(12)60322-5

3. Madge N, Hewitt A, Hawton K, de Wilde EJ, Corcoran P, Fekete S, van Heeringen K, De Leo D, Ystgaard M (2008) Deliberate self-harm within an international community sample of young people: comparative findings from the Child \& Adolescent Self-harm in Europe (CASE) Study. J Child Psychol Psychiatry 49(6):667-677. https://doi.org/10.1111/j.1469-7610.2008.01879 .X

4. Kessler RC, Borges G, Walters EE (1999) Prevalence of and risk factors for lifetime suicide attempts in the National Comorbidity Survey. Arch Gen Psychiatry 56(7):617-626

5. Fergusson DM, Horwood LJ, Ridder EM, Beautrais AL (2005) Suicidal behaviour in adolescence and subsequent mental health outcomes in young adulthood. Psychol Med 35(7):983-993

6. Kerr DC, Capaldi DM (2011) Young men's intimate partner violence and relationship functioning: long-term outcomes associated with suicide attempt and aggression in adolescence. Psychol Med 41(4):759-769. https://doi.org/10.1017/S0033291710001182

7. Goldman-Mellor SJ, Caspi A, Harrington H, Hogan S, Nada-Raja S, Poulton R, Moffitt TE (2014) Suicide attempt in young people: a signal for long-term health care and social needs. JAMA Psychiatry 71(2):119-127. https://doi.org/10.1001/jamapsychi atry.2013.2803

8. Niederkrotenthaler T, Tinghog P, Alexanderson K, Dahlin M, Wang M, Beckman K, Gould M, Mittendorfer-Rutz E (2014) Future risk of labour market marginalization in young suicide attempters-a population-based prospective cohort study. Int $\mathbf{J}$ Epidemiol 43(5):1520-1530. https://doi.org/10.1093/ije/dyu155

9. Briere FN, Rohde P, Seeley JR, Klein D, Lewinsohn PM (2015) Adolescent suicide attempts and adult adjustment. Depress Anxiety 32(4):270-276. https://doi.org/10.1002/da.22296 
10. Beckman K, Mittendorfer-Rutz E, Lichtenstein P, Larsson H, Almqvist C, Runeson B, Dahlin M (2016) Mental illness and suicide after self-harm among young adults: long-term follow-up of self-harm patients, admitted to hospital care, in a national cohort. Psychol Med 46(16):3397-3405. https://doi.org/10.1017/S0033 291716002282

11. Beautrais AL (2002) Gender issues in youth suicidal behaviour. Emerg Med (Fremantle) 14(1):35-42

12. Bresin K, Schoenleber M (2015) Gender differences in the prevalence of nonsuicidal self-injury: a meta-analysis. Clin Psychol Rev 38:55-64. https://doi.org/10.1016/j.cpr.2015.02.009

13. Canetto SS, Sakinofsky I (1998) The gender paradox in suicide. Suicide Life Threat Behav 28(1):1-23

14. Schrijvers DL, Bollen J, Sabbe BG (2012) The gender paradox in suicidal behavior and its impact on the suicidal process. J Affect Disord 138(1-2):19-26. https://doi.org/10.1016/j.jad.2011.03.050

15. Mortier P, Demyttenaere K, Auerbach RP, Green JG, Kessler RC, Kiekens G, Nock MK, Bruffaerts R (2015) The impact of lifetime suicidality on academic performance in college freshmen. J Affect Disord 186:254-260. https://doi.org/10.1016/j.jad.2015.07.030

16. Groholt B, Ekeberg O (2009) Prognosis after adolescent suicide attempt: mental health, psychiatric treatment, and suicide attempts in a nine-year follow-up study. Suicide Life Threat Behav 39(2):125-136. https://doi.org/10.1521/suli.2009.39.2.125

17. Larkin C, Di Blasi Z, Arensman E (2014) Risk factors for repetition of self-harm: a systematic review of prospective hospitalbased studies. PloS one 9(1):e84282. https://doi.org/10.1371/journ al.pone. 0084282

18. Oliver MI, Pearson N, Coe N, Gunnell D (2005) Help-seeking behaviour in men and women with common mental health problems: cross-sectional study. Br J Psychiatry J Mental Sci 186:297301. https://doi.org/10.1192/bjp.186.4.297

19. Moller-Leimkuhler AM (2002) Barriers to help-seeking by men: a review of sociocultural and clinical literature with particular reference to depression. J Affect Disord 71(1-3):1-9

20. Olsson GI, von Knorring AL (1999) Adolescent depression: prevalence in Swedish high-school students. Acta Psychiatr Scand 99(5):324-331

21. Breslau J, Gilman SE, Stein BD, Ruder T, Gmelin T, Miller E (2017) Sex differences in recent first-onset depression in an epidemiological sample of adolescents. Transl Psychiatry 7(5):e1139. https://doi.org/10.1038/tp.2017.105

22. Hawton K, Saunders K, Topiwala A, Haw C (2013) Psychiatric disorders in patients presenting to hospital following self-harm: a systematic review. J Affect Disord 151(3):821-830. https://doi. org/10.1016/j.jad.2013.08.020

23. Hyde JS, Mezulis AH, Abramson LY (2008) The ABCs of depression: integrating affective, biological, and cognitive models to explain the emergence of the gender difference in depression. Psychol Rev 115(2):291-313. https://doi. org/10.1037/0033-295X.115.2.291

24. Mars B, Heron J, Crane C, Hawton K, Lewis G, Macleod J, Tilling K, Gunnell D (2014) Clinical and social outcomes of adolescent self harm: population based birth cohort study. BMJ 349:g5954. https://doi.org/10.1136/bmj.g5954

25. Niederkrotenthaler T, Tinghog P, Goldman-Mellor S, Wilcox HC, Gould M, Mittendorfer-Rutz E (2016) Medical and social determinants of subsequent labour market marginalization in Young hospitalized suicide attempters. PloS One 11(1):e0146130. https ://doi.org/10.1371/journal.pone.0146130

26. Moran P, Coffey C, Romaniuk H, Degenhardt L, Borschmann R, Patton GC (2015) Substance use in adulthood following adolescent self-harm: a population-based cohort study. Acta Psychiatr Scand 131(1):61-68. https://doi.org/10.1111/acps.12306

27. Farbstein I, Dycian A, Gothelf D, King RA, Cohen DJ, Kron S, Apter A (2002) A follow-up study of adolescent attempted suicide in Israel. J Am Acad Child Adolesc Psychiatry 41(11):1342-1349. https://doi.org/10.1097/00004583-200211000-00016

28. Cooper J, Kapur N, Webb R, Lawlor M, Guthrie E, MackwayJones K, Appleby L (2005) Suicide after deliberate self-harm: a 4-year cohort study. Am J Psychiatry 162(2):297-303. https://doi. org/10.1176/appi.ajp.162.2.297

29. Skogman K, Alsen M, Ojehagen A (2004) Sex differences in risk factors for suicide after attempted suicide-a follow-up study of 1052 suicide attempters. Soc Psychiatry Psychiatr Epidemiol 39(2):113-120. https://doi.org/10.1007/s00127-004-0709-9

30. Hawton K, Harriss L, Zahl D (2006) Deaths from all causes in a long-term follow-up study of 11,583 deliberate self-harm patients. Psychol Med 36(3):397-405. https://doi.org/10.1017/S003329170 5006914

31. Neeleman J, Wessely S (1997) Changes in classification of suicide in England and Wales: time trends and associations with coroners' professional backgrounds. Psychol Med 27(2):467-472

32. Arcelus J, Claes L, Witcomb GL, Marshall E, Bouman WP (2016) Risk factors for non-suicidal self-injury among trans youth. J Sex Med 13(3):402-412. https://doi.org/10.1016/j.jsxm.2016.01.003

33. Marshall E, Claes L, Bouman WP, Witcomb GL, Arcelus J (2016) Non-suicidal self-injury and suicidality in trans people: a systematic review of the literature. Int Rev Psychiatry 28(1):58-69. https ://doi.org/10.3109/09540261.2015.1073143

34. Zucker KJ, Lawrence AA (2009) Epidemiology of gender identity disorder: recommendations for the standards of care of the world professional association for transgender health. Int J Transgenderism 11(1):8-18. https://doi.org/10.1080/15532730902799946 